\title{
Estimativas de perdas econômicas causadas por reação granulomatosa local após uso de vacina oleosa contra febre aftosa em bovinos de Mato Grosso do Sul ${ }^{1}$
}

\author{
Paula V. Leal ${ }^{2}$, Rayane C. Pupin ${ }^{2}$, Ariany C. Santos ${ }^{3}$, Tatiane C. Faccin ${ }^{3}$, Eduardo Surdi ${ }^{4}$, \\ Cassia R.B. Leal ${ }^{5}$, Ricardo Carneiro Brumatti ${ }^{5}$ e Ricardo A.A. Lemos ${ }^{5 *}$
}

\begin{abstract}
Leal P.V., Pupin R.C., Santos A.C., Faccin T.C., Surdi E., Leal C.R.B., Brumatti R.C. \& Lemos R.A.A. 2014. [Estimates of economic losses caused by local granulomatous reaction after use of an oily vaccine against FMD in cattle of Mato Grosso do Sul. Estimativas de perdas econômicas causadas por reação granulomatosa local após uso de vacina oleosa contra febre aftosa em bovinos de Mato Grosso do Sul. Pesquisa Veterinária Brasileira 34(8):738-742. Faculdade de Medicina Veterinária e Zootecnia, Universidade Federal de Mato Grosso do Sul, Avenida Senador Filinto Müller 2443, Campo Grande, MS 79074-460, Brazil. E-mail: lap.famez@ufms.br

Lesions caused by excessive reaction to foot and mouth vaccine were observed in 1,815 out of 5,000 cattle slaughtered in a slaughterhouse under federal meat inspection. Such lesions resulted in condemnation of the affect parts of the carcasses in accordance with the Brazilian Federal Meat Inspection Regulations. The affected cattle had been vaccinated on May 2012 and then slaughtered in September of the same year. They were allotted to two groups with 1,500 (Groups 1) and 315 cattle (Group 2). Post vaccination lesions were characterized as salient, firm variable sized nodules multifocally distributed in the musculature of the lateral neck. Pus oozed at the cut surface of these nodules. Samples of 28 cattle were submitted for histopathological examination; main findings were pyogranulomas with central variable-sized clear spaces surrounded by marked infiltrate of viable and dead neutrophils, which were surrounded by epithelioid macrophages with vacuolated cytoplasm and occasional multinucleated giant cell. This inflammatory reaction was walled by abundant connective tissue infiltrated by lymphocytes and plasma cells. Samples of the lesion of six cattle were submitted to bacteriological culture with negative results. When affected carcasses went through dressing, there was an average of 1.8 and $2.0 \mathrm{~kg}$ of muscle tissue cut off from the carcasses respectively of Group 1 and 2. Economic losses in the farm of origin of the affected cattle was $\mathrm{R} \$ 20,424.00$, considering the price paid by $\mathrm{kg}$ of cattle for slaughter at the time of the occurrence. This amount at that time was enough to buy 29.17 weaned calves for fattening. If one considers theses 5,000 cattle vaccinated on the farm as the population at risk, the morbidity rate would be $0.36 \%$. These results indicate that the losses due to vaccine reaction, even with no overt clinical signs, may cause important economic losses.
\end{abstract}

INDEX TERMS: Economic losses, vaccine reaction, foot-and-mouth disease, oil adjuvant, vaccine granulomas, cattle.

\footnotetext{
${ }^{1}$ Recebido em 13 de abril de 2014.

Aceito para publicação em 15 de julho de 2014.

${ }^{2}$ Residência Profissional em Medicina Veterinária, Faculdade de Medicina Veterinária e Zootecnia (FAMEZ), Universidade Federal de Mato Grosso do Sul (UFMS), Av. Senador Filinto Müller 2443, Campo Grande, MS 79074-460, Brasil.
}

\footnotetext{
${ }^{3}$ Programa de Pós-Graduação em Ciência Animal, FAMEZ/UFMS, Campo Grande, MS.

${ }^{4}$ Médico Veterinário Autônomo, Av. Seis 333, Chapadão do Sul, MS 79560-000, Brasil.

${ }^{5}$ FAMEZ/UFMS, Campo Grande, MS. *Autor para correspondência: lap.famez@ufms.br
} 
RESUMO.- Lesões exacerbadas à vacina contra a febre aftosa foram observadas em 1.815 de um total de 5.000 bovinos abatidos em frigorífico com inspeção federal. Essas lesões resultaram na condenação de parte das carcaças de acordo com o Regulamento da Inspeção Industrial e Sanitária de Produtos de Origem Animal. Os bovinos haviam sido vacinados em maio de 2012 e abatidos em setembro do mesmo ano e divididos em Lotes 1 e 2 constituídos respectivamente por 1.500 e 315 bovinos. As lesões de reação vacinal eram caracterizadas por nódulos protuberantes, circunscritos, bem delimitados, firmes e de tamanhos variáveis, distribuídos multifocalmente na musculatura do aspecto lateral do pescoço; ao corte apresentavam exsudato purulento. Amostras da lesão de 28 bovinos foram avaliadas histologicamente e os principais achados foram piogranulomas com espaços claros circulares de tamanhos variados no centro, circundados por intenso infiltrado de neutrófilos íntegros e necróticos, circundados por macrófagos epitelioides com citoplasma vacuolizado, ocasionais células gigantes multinucleadas e, mais externamente, por abundante tecido conjuntivo em meio observavam-se linfócitos e plasmócitos. Culturas bacterianas realizadas em amostras do exsudato da lesão de seis bovinos resultaram negativas. Quando as carcaças afetadas foram submetidas ao toalete foi retirado em média 1,8 e 2,0 kg de músculo da área afetada, respectivamente dos Lotes 1 e 2.0 prejuízo econômico da propriedade de origem dos bovinos afetados foi de $\mathrm{R} \$ 20.424,00$, considerando o preço pago pela arroba do boi no mês e ano da ocorrência. Esses valores à época seriam suficientes para adquirir 29,17 bezerros desmamados para engorda. Se considerarmos 5.000 bovinos vacinados forem considerados como população sob risco o coeficiente de morbidade seria de $0,36 \%$. Os resultados deste estudo demonstram que perdas por reação vacinal, mesmo quando não provocam sinais clínicos marcantes, podem ocasionar importantes prejuízos econômicos.

TERMOS DE INDEXAÇÃO: Perdas econômicas, reação vacinal, febre aftosa, adjuvante oleoso, granulomas pós-vacinais, bovinos.

\section{INTRODUÇÃO}

O Brasil é o segundo maior produtor de carne bovina no mundo, com mais de 209 milhões de cabeças, ficando atrás apenas dos EUA. A região Centro-oeste detém 34,6\% do efetivo nacional, sendo esta a região que mais produz carne no país. No contexto nacional, Mato Grosso do Sul (MS) é responsável por $10,7 \%$ da produção de carne bovina (IBGE 2011). 0 aumento nas taxas de exportação de carne bovina foi devido, dentre outros fatores, aos programas de controle epidemiológico para doenças de notificação obrigatória. Dentre as medidas propostas nestes programas, a vacinação sistemática preventiva, seguindo o calendário definido pelo Ministério da Agricultura Pecuária e Abastecimento (MAPA), torna o uso de vacinas um manejo rotineiro nas propriedades. No entanto, a utilização destas pode acarretar reações adversas incluindo reações anafiláticas, infecções iatrogênicas, granulomas pós-vacinais, danos teciduais ocasionados por endotoxinas, reação inflamatória aguda e polirradiculoneuropatia desmielinizante (O’Toole et al. 1995), e em consequência a essas reações há significativas perdas econômicas (França Filho et al. 2006).

0 objetivo deste trabalho foi estimar as perdas econômicas por reação granulomatosa após o uso de vacina oleosa contra febre aftosa em um rebanho bovino abatido no município de Cassilândia, Mato Grosso do Sul (MS).

\section{MATERIAL E MÉTODOS}

Foram avaliadas no momento do abate, 1815 carcaças, de um total de 5000, com histórico de reação granulomatosa exacerbada após vacinação contra febre aftosa, que resultaram na condenação de parte das carcaças de acordo com o predito no RIISPOA. Segundo o médico veterinário responsável, os bovinos foram vacinados no mês de Maio e seguiu-se os mesmos procedimentos realizados em anos anteriores, nos quais não ocorreram reações vacinais exacerbadas, sendo a única alteração a mudança do produto comercial utilizado para a imunização contra febre aftosa.

Considerando que todas possuíam as mesmas características macroscópicas, e para não prejudicar a rotina da inspeção, foram coletadas amostras de vinte e oito carcaças para avaliação histológica. Estas foram fixadas em formol a $10 \%$ e foram processadas rotineiramente para exame histológico e coradas com hematoxilina e eosina (H\&E) pelo Laboratório de Anatomia Patológica(LAP), da Faculdade de Medicina Veterinária e Zootecnia (FAMEZ), Universidade Federal do Mato Grosso do Sul (UFMS). Seis amostras do exsudato das lesões foram coletadas com swab (meio Stuart estéril para transporte) e encaminhadas ao Laboratório de Bacteriologia da FAMEZ/UFMS, onde foram semeadas em meios enriquecidos para cultivo bacteriano.

Para a estimativa média de perdas por lote abatido as amostras condenadas foram pesadas sendo calculada a média de peso por lote. 0 prejuízo financeiro da propriedade foi calculado somando-se o total de quilos de carne perdida multiplicado pelo preço do quilo de boi gordo pago ao produtor rural no estado de MS, no mês e ano de realização do estudo. 0 valor obtido foi transformado em cabeças de boi gordo e cabeças de bezerros que representam a renúncia financeira ocorrida na comercialização. Foi realizada uma análise de sensibilidade oscilando-se o valor do quilo de boi gordo obtendo-se com isso três cenários, cenário padrão, cenário com valor do quilo no teto e cenário com valor do quilo no piso para o mercado nacional, considerando os valores do CEPEA/ESALQ (2012).

No ano seguinte aos casos de condenação por reação vacinal, a propriedade foi acompanhada pela equipe do LAP/FAMEZ. Salienta-se que no ano de 2013 houve retorno ao produto comercial utilizado antes das reações vacinais observadas em 2012.

\section{RESULTADOS}

A propriedade rural localizada no município Chapadão do Sul, MS, possuía 13.000 bovinos confinados, dos quais 5.000 foram vacinados, por via subcutânea, com uma vacina comercial contra Febre Aftosa, com adjuvante oleoso, durante a campanha de maio de 2012. Esses bovinos foram abatidos em dois lotes (Lote 1 e Lote 2) em um frigorífico localizado no município de Cassilândia, MS.

Os bovinos estavam sadios e ao abate foram observados nódulos na face lateral do pescoço, protuberantes, circunscritos, bem delimitados, firmes, de tamanhos variáveis, distribuídos multifocalmente na musculatura e ao corte apresentavam material purulento (Fig.1). Inicialmente, foram remetidas oito amostras (Lote 1) pelo veterinário responsável pela propriedade. As demais vinte amostras 


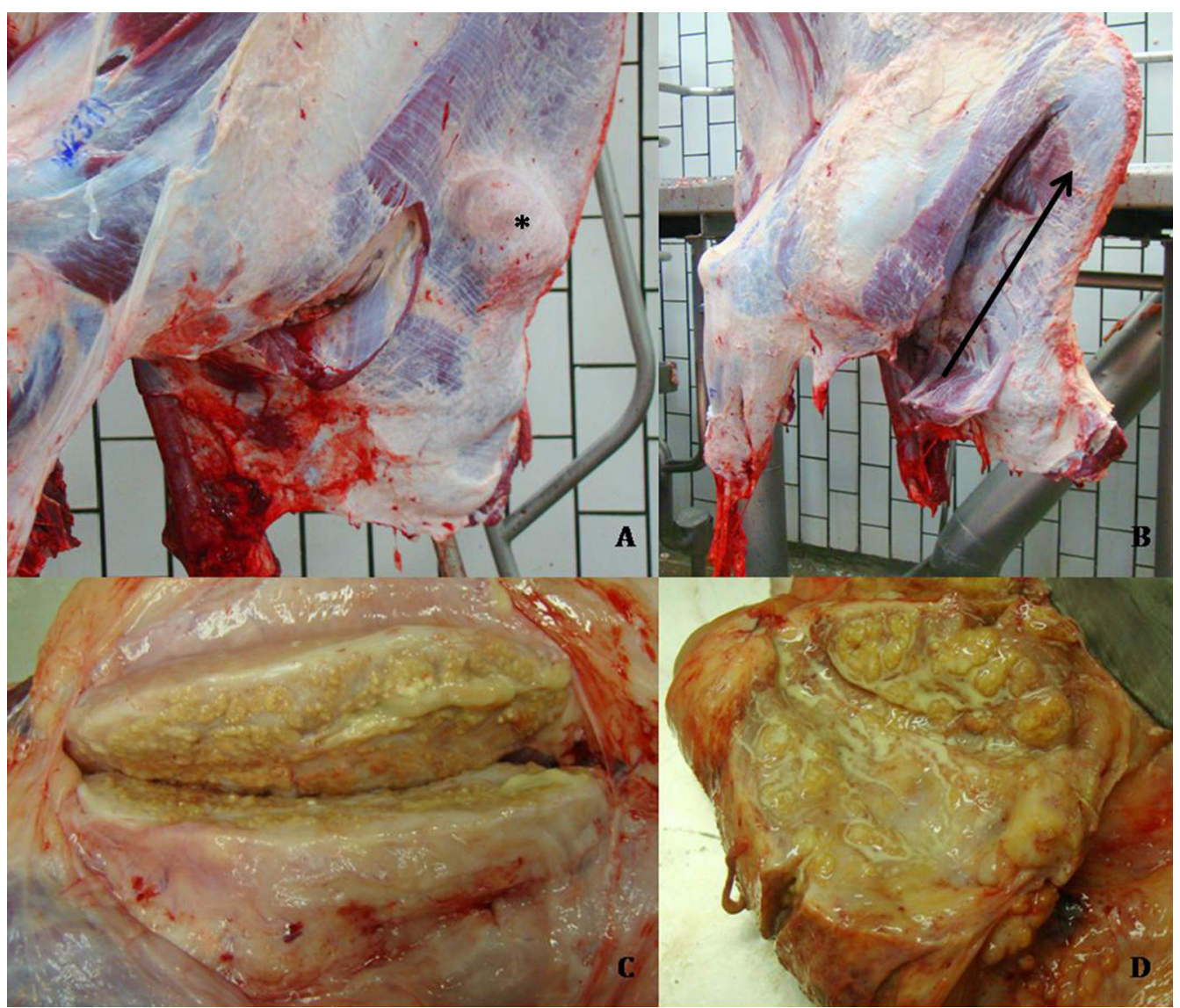

Fig.1. Bovino. Reação vacinal granulomatosa. (A) Hemi-carcaça bovina com nódulo (asterisco), protuberante, circunscrito e bem delimitado na região do pescoço antes do toalete e (B) após o toalete (seta). (C,D) Aspecto macroscópico de nódulos por reação granulomatosa, firmes e bem delimitados com discreto exsudato purulento.

\section{Quadro1. Resultados econômicos obtidos no caso relatado e na análise de sensibilidade} realizada

\begin{tabular}{lccc}
\hline Parâmetros & Caso relatado & $\begin{array}{c}\text { Teto do valor do kg } \\
\text { de boi gordo }\end{array}$ & $\begin{array}{c}\text { Piso do valor do kg } \\
\text { de boi gordo }^{\text {a }}\end{array}$ \\
\hline $\begin{array}{l}\text { Valor pago pelo quilo de boi } \\
\text { gordo (R\$/kg) }\end{array}$ & 6,13 & 6,67 & 5,87 \\
Prejuízo Total Estimado (R\$) & $20.412,90$ & $22.211,10$ & $19.547,10$ \\
Variação do Prejuízo (\%) & & $+8,80$ & $-4,24$ \\
Equivalente em Bezerros & 29,16 & 31,73 & 27,92
\end{tabular}

a CEPEA/ESALQ (2012); Média da cotação do dólar no mês de setembro de $2012=\mathrm{R} \$ 2,03$.

foram coletadas aleatoriamente pela equipe do LAP/FAMEZ durante o abate (Lote 2) e fixadas em formol a $10 \%$. O Lote 1 era constituído por 3.000 bovinos e o Lote 2 por 350 bovinos.

Do total de animais abatidos, 1.500 bovinos do Lote 1 e 315 bovinos do Lote 2 apresentavam lesões características de reação vacinal no músculo trapézio e quando essas carcaças eram submetidas ao toalete retirava-se em média de 1,8 $\mathrm{kg}$ (Lote 1) a 2,0 kg (Lote 2) de músculo na área afetada.

Microscopicamente foram observados espaços circulares translúcidos de tamanhos variados, que correspondiam ao acúmulo de adjuvante lipídico da vacina removido no processamento histológico, circundados por intenso infiltrado de neutrófilos viáveis e degenerados, linfócitos e plasmócitos. Ao redor, havia macrófagos epitelioides com citoplasma contendo vesículas translúcidas, abundante tecido conjuntivo delimitando os granulomas e algumas células gigantes multinucleadas (Fig. 2). Em alguns fragmentos, havia formações granulomatosas nas quais o centro era constituído de material necrótico. No tecido muscular esquelético adjacente havia discreta a moderara degeneração flocular das miofibras, intercalada com áreas focais de hemorragia.

Nas seis amostras encaminhadas para a análise microbiológica não houve crescimento bacteriano. Durante o acompanhamento da propriedade no ano seguinte não houve casos de reação vacinal exacerbada como as descritas neste relato no ano de 2012. Os resultados econômicos são demonstrados no Quadro 1. 


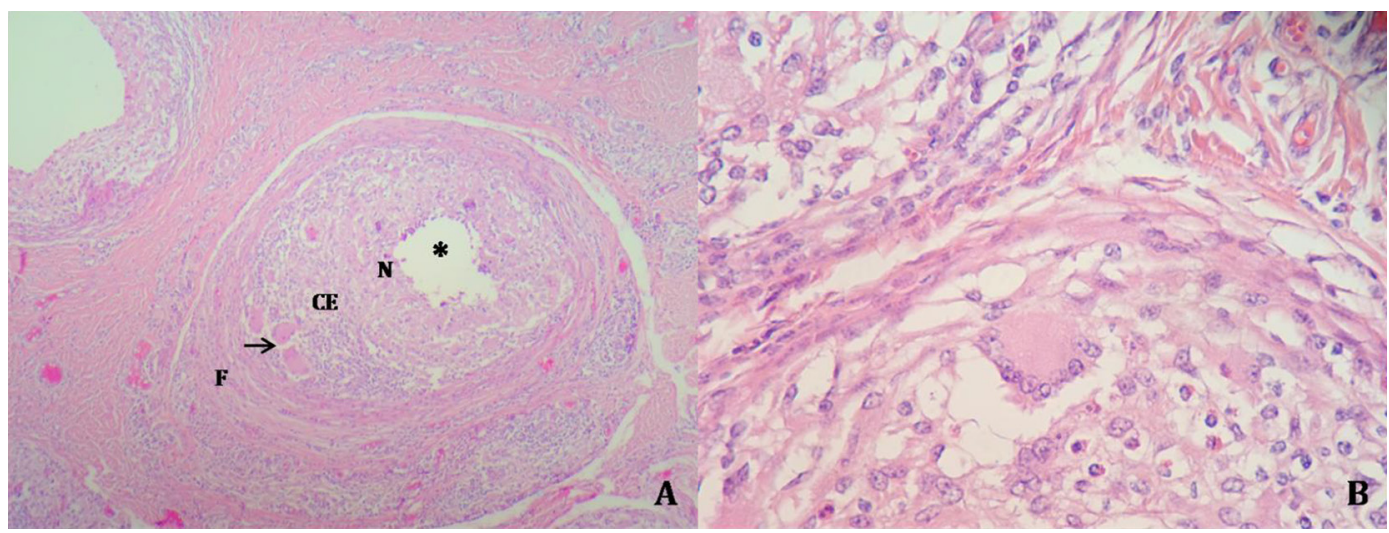

Fig.2. Bovino. Granuloma vacinal. (A) Aspecto histológico caracterizado por área central esférica clara (asterisco) correspondente ao adjuvante oleoso da vacina contra febre aftosa, circundada por infiltrado de neutrófilos $(\mathrm{N})$, seguido de células epitelioides $(\mathrm{CE})$, poucas células gigantes multinucleadas (seta) e fibrose periférica (F). HE, obj.10x. (B) Ao centro, célula gigante multinucleada e ao redor há células epitelioides com citoplasma contendo espaços circulares translúcidos e discreta fibrose. HE, obj.40x.

\section{DISCUSSÃO E CONCLUSÕES}

O diagnóstico de reação vacinal baseou-se nas características macroscópicas e histológicas das lesões, que eram similares àquelas descritas em bovinos em relatos anteriores (O’Toole et al. 1995, Ubiali et al. 2011, Marques et al. 2012). Além das características histopatológicas, a possibilidade de contaminação bacteriana foi descartada pelos resultados negativos das culturas microbiológicas realizadas.

Segundo o artigo 157. do Regulamento da Inspeção Industrial e Sanitária de Produtos de Origem Animal (RIISPOA), quando as carcaças apresentam lesões localizadas, como abscessos ou lesões supuradas, devem ser condenadas apenas as partes atingidas (Brasil 1952). No abate, a condenação ocorre pela identificação visual de áreas elevadas e não é realizada a abertura da lesão. Desta forma, não foi possível precisar se as lesões no músculo eram abscedativas ou granulomatosas. 0 serviço de inspeção responsável pelo frigorífico seguiu o preconizado pela legislação vigente, sendo retirada a porção da musculatura atingida pelas lesões.

Neste caso, a perda média foi de 1,8 $\mathrm{kg}$ (Lote 1) e 2,0 kg (Lote 2) de músculo da região afetada, representando um total de $2.700 \mathrm{~kg}$ para o Lote 1 e $630 \mathrm{~kg}$ para o Lote 2 , o que equivale ao peso médio de abate de doze bovinos de 24 a 36 meses (530 kg por animal). Considerando-se a população sob risco os 5.000 bovinos vacinados, esses dados corresponderiam a um coeficiente de morbidade de $0,36 \%$. Embora aparentemente baixo este coeficiente é semelhante ao encontrado na maioria dos surtos por doenças responsáveis por importantes perdas econômicas em bovinos no MS, como a raiva e o botulismo (Ribas et al. 2013). Levando em conta o valor pago ao produtor pelo quilo do boi abatido, que em setembro de 2012 era de $\mathrm{R} \$ 6,13$ (CEPEA/ ESALQ 2012), a perda total correspondeu a $\mathrm{R} \$ 20.412,90$. Esses valores na época acima citada seriam suficientes para adquirir 29,16 bezerros desmamados para engorda no valor de $\mathrm{R} \$ 700,00$ cada (CEPEA/ESALQ 2012). A análise de sensibilidade realizada demonstrou uma variação percentual de $+8,80 \%$ a $-4,24 \%$, quando se considerou o teto pago pelo quilo de boi gordo em $\mathrm{R} \$ 6,67$ e o piso em $\mathrm{R} \$$ 5,87 (CEPEA/ESALQ, 2012). Comparados ao cenário relatado, isto representaria prejuízos na ordem de no mínimo $R \$ 19.547,10$ a até $R \$ 22.211,10$. Prejuízo este que pode ser convertido em quantidades de cabeças de bezerros, variando de 27,92 a até 31,73 cabeças a menos, respectivamente, a cada cenário testado.

Ressalta-se que no presente trabalho, o LAP/FAMEZ foi solicitado para acompanhar os casos de condenação por reação vacinal, acima dos padrões observados em anos anteriores, em uma única propriedade rural. Estudos anteriores realizados com amostras de diferentes propriedades em outros estados encontraram valores de perdas por animal entre 0,039 $\mathrm{kg}$ e 0,852 $\mathrm{kg}$ (França Filho et al. 2006, Assis et al. 2011).

Salienta-se no presente caso que as reações vacinais não ocasionaram outros sinais clínicos, porém, quadros clínicos graves podem ser associados a reações vacinais, especialmente quando a vacina é aplicada em locais não indicados (Ubiali et al. 2011). Em dois relatos anteriores, a aplicação de vacina em região corporal inadequada resultou em distúrbios neurológicos em 25 de 3000 bovinos (Ubiali et al. 2011), em 18 bovinos de quatro propriedades do estado de Pernambuco e em seis bovinos de um lote de 100 animais na Paraíba (Marques et al. 2012). Esses sinais clínicos devem-se a proximidade anatômica da região afetada com a medula espinhal. Assim como no presente estudo, nesses relatos anteriores não houve contaminação bacteriana e as lesões foram atribuídas a reação vacinal.

Embora não seja possível determinar com precisão a causa da gravidade das lesões vacinais é possível que a mesma esteja relacionada às características próprias no adjuvante presente na formulação da vacina, pois não havia histórico de reações adversas tão intensas nos anos anteriores quando outra vacina comercial era aplicada e, também, não foram observadas reações no ano seguinte quando o produto associado ao surto foi substituído pelo anteriormente utilizado. As reações granulomatosas ocorrem por adjuvantes oleosos, que na grande maioria, são compostos 
por emulsão oleosa que induzem uma reação inflamatória local crônica, culminando com a formação de granulomas ou abscessos ao redor da substância inoculada, com antígenos liberados lentamente da fase aquosa (Tizard 2002). Estes granulomas imunológicos caracterizam-se pela presença de células epitelioides (macrófagos ativados) que podem fusionar-se formando células multinucleadas, linfócitos e fibroblastos (Schmitt \& Scroferneker 2007).

Os resultados do presente trabalho demonstram que as perdas por reação vacinal, mesmo quando não provocam quadros clínicos graves responsáveis pela morte dos animais, podem ocasionar importantes prejuízos econômicos. Merece destaque o fato de que estas reações podem ocorrer mesmo quando a vacinação é realizada de forma adequada, devido às características do adjuvante empregado em sua formulação. Esses resultados reforçam a necessidade de um rígido controle de qualidade pela indústria farmacêutica de modo que as vacinas formuladas para a prevenção da febre aftosa não apenas garantam níveis satisfatórios de imunidade, mas também minimizem as possíveis reações adversas.

\section{REFERÊNCIAS}

Assis D.R., Rezende-Lago N.C.M., Marchi P.G.F. \& D’Amato M. 2011. Perdas diretas ocasionadas por abscessos e hematomas em carcaças de bovinos. Revta Port. Ciênc. Vet. 110(577/580):47-51.

Brasil 1952. Decreto lei no30.691, de 29 de março de 1952, alterado pelos Decretos no 1255, de 25 junho de 1962, no 1.236, de 2 de setembro de 1994, e no 1.812, de 8 de fevereiro de 1996, e no 2.244 de 4 de junho de 1997. Regulamento da Inspeção Industrial e Sanitária de Produtos de Origem Animal, Divisão de Normas Técnicas-DNT, Departamento de
Inspeção de Produtos de Origem Animal DIPOA, Secretaria de Defesa Agropecuária-DAS, Ministério da Agricultura e do Abastecimento, Brasília, DF. 241p.

CEPEA/ESALQ. 2012. Informativo no 21. Custo de produção da pecuária de corte. Universidade de São Paulo, Escola Superior de Agricultura Luiz de Queiroz (ESALQ). Edição 21. Disponível em <http://cepea.esalq.usp. br/boi/> Acesso em 5 dez. 2013.

França Filho A.T., Alves G.G., Mesquita A.J., Chiquetto C.E., Bueno C.P. \& Cruz A.S. 2006. Perdas econômicas por abcessos vacinais e/ou medicamentosos em carcaças de bovinos abatidos no estado de Goiás. Ciênc. Anim. Bras. 7(1):93-96.

IBGE 2011. Diretoria de Pesquisas, Coordenação de Agropecuária, Pesquisa da Pecuária Municipal, Fundação Instituto Brasileiro de Geografia e Estatística. <ftp://ftp.ibge.gov.br/Producao_Pecuaria/Producao_da_Pecuaria_Municipal/2011/tabelas_pdf/tab03.pdf> Acesso em 2 dez. 2013.

Marques A.L.A., Simões S.V.D., Maia L.A., Silva T.R., Miranda Neto E.G., Pimentel L.A., Afonso J.A.B. \& Dantas A.C. 2012. Compressão medular em bovinos associada à vacinação contra febre aftosa. Ciência Rural 42(10):1851-1856.

O’Toole D., McAllister M.M. \& Griggs K. 1995. Iatrogenic compressive lumbar myelopathy and radiculopathy in adult cattle following injection of an adjuvanted bacterin into loin muscle: histopathology and ultrastructure. J. Vet. Diagn. Invest. 7:237-244.

Tizard I.R. 2002. Imunologia Veterinária: uma introdução. 6⿳a ed. Roca, São Paulo, p.271-280.

Ribas N.L.K.S., Carvalho R.I., Santos A.C., Valençoela R.A., Gouveia A.F., Castro M.B., Mori A.E. \& Lemos R.A.A. 2013. Doenças do sistema nervoso de bovinos no Mato Grosso do Sul: 1082 casos. Pesq. Vet. Bras. 33(10):1183-1194.

Schmitt J.R. \& Scroferneker M.L. 2007. Imunologia Básica e Aplicada. 2ª ed. Segmento Farma, São Paulo, p.205-210.

Ubiali D.G., Cruz R.A.S., Lana M.V.C., Meireles Y.S., Néspoli P.B., Souza M.A., Colodel E.M. \& Pescador C.A. 2011. Spinal cord compression in cattle after the use an oily vaccine. Pesq. Vet. Bras. 31(11):997-999. 